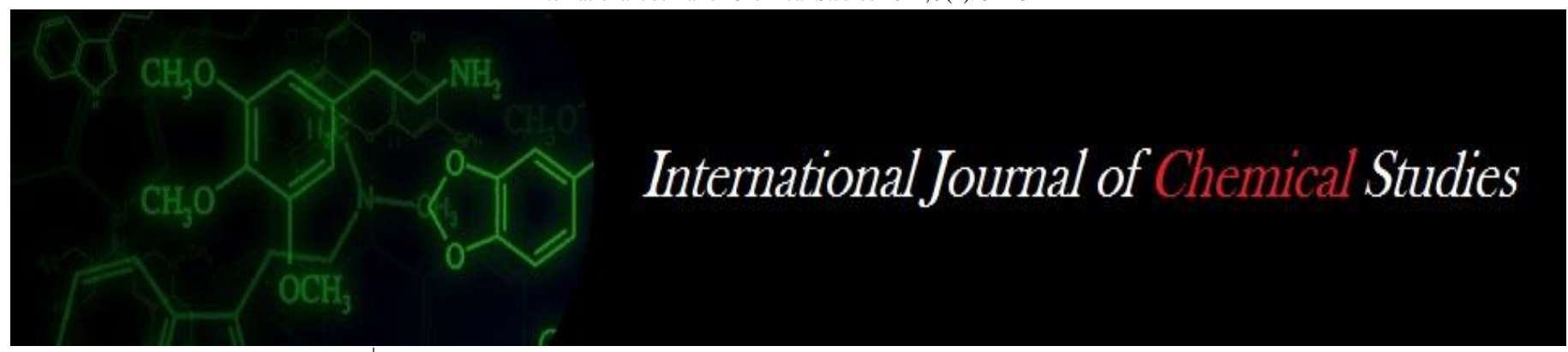

P-ISSN: 2349-8528

E-ISSN: 2321-4902

www.chemijournal.com

IJCS 2021; 9(1): 542-544

(C) 2021 IJCS

Received: 03-10-2020

Accepted: 29-11-2020

Pooja Choudhary

School of Agriculture,

Department of Agronomy,

Lovely Professional University,

Phagwara, Punjab, India

Anaytullah Siddique

School of Agriculture,

Department of Agronomy,

Lovely Professional University,

Phagwara, Punjab, India

\section{Role of potassium solubilizing bacteria in crop production: An overview}

\author{
Pooja Choudhary and Anaytullah Siddique
}

DOI: https://doi.org/10.22271/chemi.2021.v9.i1h.11284

\begin{abstract}
Potassium is one of the essential nutrients required by plant for multiple purposes like growth of root and stem, activation of enzymes, opening and closing of stomata, triggers osmoregulatory process etc. It is abundant in soil but most of the time unavailable to the plants because of its availability in bound or adsorbed forms. Many strains of microbes present in soil act on insoluble form of potassium to solubilize or mobilize this form to available form known as potassium solubilizing bacteria (KSB). The soil which is deficient or excess in potassium, the application of such strains of microbes enhanced the availability of potassium to the plant. Use of such microbes is found very effective in maintaining the availability of potassium nutrient to the crop while decreases the dependency on inorganic fertilizers for compensating the demand of plants. Nowadays, the role of KSB is widely accepted hence it can help to maintain the availability of potassium as well as enhance the production of crop.
\end{abstract}

Keywords: Biofertilizer, KSB, microorganisms, rhizosphere and stress

\section{Introduction}

Potassium is the third most important plant nutrient after nitrogen and phosphorus. It has a wide range of function in plant life in which some of the valuable functions are develop tolerance capacity by triggering osmoregulatory process, activate enzymes related to energy metabolism, photosynthesis and starch synthesis. Out of all the amount of potassium present in the earth crust, only $1-2 \%$ is available to the plant while rest amount of potassium is present in the bounded form. It presents in four most popular forms in soil i.e. mineral, nonexchangeable, and exchangeable and solution in which $90-98 \%$ is in mineral form which is unavailable to plants (Etesami et al., 2017 and Sparks and Huang, 1985) ${ }^{[5]}$. The nonexchangeable form varies between 1-10\% which present between the layers of clay (Etesami et al., 2017; Sparks, 1987 and Sparks and Huang, 1985) ${ }^{[5]}$. Various kinds of microorganisms survive in rhizospheric and non-rhizospheric zone of soil while the plant is getting affected by rhizospheric microbes where they are able to influence soil fertility by influencing the processes like nutrient release, decomposition, mineralization, immobilization (Zahra et al., 1984 and Parmar and Sindhu, 2013). There are some most prominent mechanism (acidolysis, polysaccharides, complexolysis, chelation) by which the beneficial soil microbes like saprophytic bacteria, fungal strains and actinomycetes solubilize insoluble forms of $\mathrm{K}$ in to soluble forms (Vandevivere et al.,1994; Barker et al., 1998). Therefore, the application of such microorganisms as $\mathrm{KSM} / \mathrm{KSB}$ ( $\mathrm{K}$ solubilizing microorganism/bacteria) is a favourable approach for enhancing the availability of $\mathrm{K}$ in soil.

\section{Potential of KSB/KSM for the yield betterment}

Enough evidence is available to show the betterment of production from seed germination to yield of crops by the use of potassium solubilizing bacteria (KSB) and potassium solubilizing microorganism (KSM). It is also reported that by the use of B. mucilaginosus strain RCBC13, the improvement is not only observe in nutrient uptake but also observe in biomass production, shoot and root growth in different crops like tomato, cotton, rape and wheat (Sheng, 2005; Anjanadevi et al., 2016; Lynn et al., 2013; Meena et al., 2014; Zhang et al., 2013; Zhang and

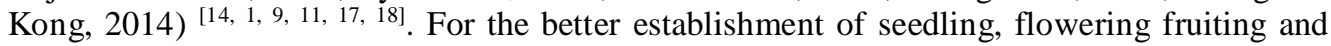
yield, a strong association among the microbes and plant roots are compulsory while each and every plant need a special strain of microbial culture.
Corresponding Author h Siddique School of Agriculture, Department of Agronomy, Lovely Professional University, Phagwara, Punjab, India 
However, the selection of suitable strain by plant roots decided by the release of exudate or signal from the plant roots. KSB is also popularly known as plant growth promoting bacteria hence it provide support to the plant in two different ways either direct way or through plant growth hormone (Chaparro et al., 2013; Ma et al., 2016; de Zelicourt et al., 2013 and Glick, 2012) ${ }^{[3,10,4,6]}$.

\section{Popolar Strains of KSB/KSM}

Bacillus mucilaginosus, Bacillus circulanscan, Bacillus edaphicus, Bacillus urkholderia, A ferrooxidans, Arthrobacter sp., Enterobacter hormaechei, Paenibacillus glucanolyticus etc. are present in considerable amount where the each of microbes act well on specific source of potassium in the soil to release the available form of potassium while out of all Bacillus mucilaginisus, Bacillus edaphicus and Bacillus circulanscan are the most prominent microbes as solubilizers that work well on Mica, $\mathrm{K}$ deficient soil silicate mineral (Basak and Biswas, 2010; Sheng, 2005 and Lian et al., 2002, Meena et al., 14) ${ }^{[2,14,8,11]}$.

\section{Role of KSB in Stress Condition}

Biotic and abiotic stress is the major constraint for the crop production in agriculture around the world. It includes wide range of stress in which environmental stresses cause very drastic situation like extreme heat and cold, flood and drought, salinity and heavy metals stress etc. potassium is third most important macro element needed by plant that affect physiological and biochemical process in favour of plants (Kandpal et al., 2018) ${ }^{[7]}$. The value of potassium fertilizer is well known for the boost up the crop production because a positive relationship between potassium fertilizer and grain yield is already reported by various scientists hence the consumption of potassium fertilizer increased rapidly (Wang et al., 2013) ${ }^{[17]}$.

A very high concentration of potassium as an ion already reported in plant cell that make plant healthy not only in normal conditions of environment but also play a vital role under stress condition. It helps to activate various enzymes responsible for the smooth conductance of photosynthesis, respiration, transpiration, minerals and water uptake and its translocation (Wang et al., 2013; Etesami et al., 2017) ${ }^{[17,5]}$. Nowadays, the use of fertilizers including potassium increased rapidly but due to the use of heavy dose of fertilizer, its bad effect is also reflecting side by side on soil health and fertility level. With the view of above requirement and its bad effect on soil, the use of potassium solubilizing microorganism (KSB) or potassium solubilizing bacteria (KSB) is the one of the best and cheap option to compensate the requirement of potassium to the plant (Zafarul-Hye, et al., 2020, and Raghavendra et al., $2020^{[16,12]}$.

\section{Methods of KSB Application}

The bio-fertilizer or potassium solubilizing bacteria (KSB) may work efficiently in the soil when it is available in optimum dose along with better strain of culture and mode of application. There are many methods already in practice like soil application, seed treatment, along with drip irrigation. Three L of KSB along with potent organic base carrier is optimum when applied in soil while $10 \mathrm{ml} \mathrm{Kg-1}$ seed along with suitable sticker as a seed treatment and $3 \mathrm{~L} \mathrm{KSB}$ liquid culture in $500 \mathrm{~L}$ water ha- 1 is optimum dose to achieve better result from the cultivated land (Shanware et al., 2014 and Raghavendra et al., 2020) ${ }^{[13,12]}$.

\section{Conclusion}

Nowadays the popularity of potassium solubilizers are increasing because of many reasons like it is cheapest, environmental-friendly and good source of natural K. Hence it increases the $\mathrm{K}$ availability and $\mathrm{K}$ use efficiency thereby not only the pressure of synthetic fertilizer is reducing but production is also improves.

\section{References}

1. Anjanadevi IP, John NS, John KS, Jeeva ML, Misra RS. Rock inhabiting potassium solubilizing bacteria from Kerala, India: characterization and possibility in chemical K fertilizer substitution. J. Basic Microbiol 2016;56:6777.

2. Basak BB, Biswas DR. Co-inoculation of potassium solubilizing and nitrogen fixing bacteria on solubilisation of waste mica and their effect on growth promotion and nutrient acquisition by a forage crop. Biol. Fertil. Soils 2010;46:641-648

3. Chaparro JM, Badri DV, Bakker MG, Sugiyama A, Manter DK, Vivanco JM. Root exudation of phytochemicals in Arabidopsis follows specific patterns that are developmentally programmed and correlate with soil microbial functions. PloS one 2013;8:e55731.

4. de Zelicourt A, Al-Yousif M, Hirt H. Rhizosphere microbes as essential partners for plant stress tolerance. Molecular Plant 2013;6:242-245.

5. Etesami H, Emami S, Alikhani HA. Potassium solubilizing bacteria (KSB): Mechanisms, promotion of plant growth, and future prospects -A review. J. Soil Sci. Plant Nutr 2017,17(4). http://dx.doi.org/10.4067/S071895162017000400005.

6. Glick BR. Plant Growth-Promoting Bacteria: Mechanisms and Applications. Scientifica 2012,963401.

7. Kandpal G, Kumar P, Siddique A. Effect of drought and improvement mechanism in rice: A Review. Annals of Agri-Bio Research 2018;23(2):150-155.

8. Lian B, Fu PQ, Mo DM, Liu CQ. A comprehensive review of the mechanism of potassium release by silicate bacteria. Acta Mineral Sin 2002;22:179-183

9. Lynn TM, Win HS, Kyaw EP, Latt ZK, Yu SS. Characterization of phosphate solubilizing and potassium decomposing strains and study on their effects on tomato cultivation. Int. J. Innov. Applied Stud 2013;3:959-966.

10. Ma Y, Oliveira RS, Freitas H, Zhang C. Biochemical and molecular mechanisms of plant-microbe-metal interactions: relevance for phytoremediation. Front. Plant Sci 2016,7.

11. Meena VS, Maurya BR, Verma JP. Does a rhizospheric microorganism enhance $\mathrm{K}+$ availability in agricultural soils. Microbiol. Res 2014;169:337-347.

12. Raghavendra M, Halli HM, Hatti V, Goud BR, Verma RK. Potassium solubilising bacteria: A sustainable management option for crop production. Agrobios Newsletter 2020;18(7):25-26.

13. Shanware AS, Surekha A, Kalkar, Trivedi MM. Potassium Solublisers: Occurrence, Mechanism and Their Role as Competent Biofertilizers. International Journal of Current microbiology and Applied Sciences 2014;3(9):622-629.

14. Sheng X. Growth promotion and increased potassium uptake of cotton and rape by a potassium releasing strain of Bacillus edaphicus. Soil Biol. Biochem 2005;37:19181922. 
15. Wang X, Mohamed I, Ali M, Abbas MHH, Shah GM, Chen F. Potassium distribution in root and non-root zones of two cotton genotypes and its accumulation in their organs as affected by drought and potassium stress conditions. Journal of plant nutrition and soil sciences 2018;182(1):72-81.

16. Zafarul-Hye M, Mudassir Aslam M, Ahamad M. Combined effect of KSB and biochar on growth indices and phosphorus, potassium and chlorophyll content in sorghum under drought stress. International Journal of Biosciences 2020;16(5):212-221.

17. Zhang AM, Zhao GY, Gao TG, Wang W, Li J, Zhang SF et al. Solubilization of insoluble potassium and phosphate by Paenibacillus kribensis CX-7: a soil microorganism with biological control potential. Afri. J Microbiol. Res 2013;7:41-47.

18. Zhang C, Kong F. Isolation and identification of potassium-solubilizing bacteria from tobacco rhizospheric soil and their effect on tobacco plants. Appl. Soil. Ecol 2014;82:18-25. 